\title{
Routine use of the intubating laryngeal mask air- way results in increased upper airway morbidity
}

\section{[L'utilisation courante du masque laryngé d'intubation augmente la morbidité} des voies aériennes supérieures]

\author{
Shinichi Kihara, ${ }^{*}$ Yuuichi Yaguchi, ${ }^{*}$ Joseph Brimacombe, $†$ Seiji Watanabe, ${ }^{*}$ Noriko Taguchi*
}

Purpose: The classic laryngeal mask airway (LMA) has a soft, silicone tube and the intubating laryngeal mask airway (ILM) has a rigid, silicone-coated steel tube. We compare postoperative pharyngolaryngeal morbidity in patients randomised to receive either device.

Methods: Sixty-five female patients (ASA physical status class I or II, aged 18-80 yr) undergoing balanced regional anesthesia for gynecological laparotomy expected to last one to two hours were randomly assigned for airway management with the LMA or ILM. Intracuff pressure was maintained at $60 \mathrm{~cm} \mathrm{H} \mathrm{H}_{2} \mathrm{O}$. Postoperative pharyngolaryngeal morbidity (sore throat, difficulty swallowing, sore mouth, sore neck/jaw, hoarseness) was assessed at two, 24 and 48 hr by blinded investigators.

Results: The number of insertion attempts and duration of anesthesia was similar between groups. Sore throat was more common for the ILM at two hours (44 vs I5\%, $P=0.0$ I), $24 \mathrm{hr}$ (59 vs $21 \%$, $P=0.008$ ) and $48 \mathrm{hr}(34$ vs 3\%, $P=0.005)$. Sore mouth was more common for the ILM at two hours ( $16 \mathrm{vs} 0 \%, P=0.02)$ and $24 \mathrm{hr}$ ( 12 vs $0 \%, P=0.04)$, but not at $48 \mathrm{hr}(6$ vs $3 \%)$. Difficulty swallowing was more common for the ILM at two hours (25 vs $0 \%$, $P=0.04)$, but not at $24 \mathrm{hr}(3 \mathrm{I}$ vs $3 \%)$ and $48 \mathrm{hr}(12$ vs $9 \%)$. There were no differences in the incidence of sore jaw/neck (ILM, 3-12\%; LMA, 0-3\%) and hoarseness (ILM, I2-31\%; LMA, 16-18\%). There was no correlation between postoperative pharyngolaryngeal morbidity and duration of anesthesia.

Conclusion: Pharyngolaryngeal morbidity is more common with the ILM than the LMA following anesthesia lasting one to two hours.

Objectif : Le masque laryngé traditionnel (ML) possède un tube de silicone mou tandis que le masque laryngé d'intubation (MLI) comporte un tube de métal rigide enrobé de silicone. Nous comparons la morbidité pharyngo-laryngée postopératoire chez des patientes qui ont accepté de recevoir, au hasard, l'un ou l'autre masque.

Méthode : Soixante-cinq femmes (d'état physique ASA I ou II, de 18 à 80 ans) devant subir une anesthésie régionale balancée pendant une laparotomie gynécologique, censée durer une ou deux heures, ont été réparties au hasard pour une intubation avec le ML ou le MLI. La pression à l'intérieur du ballonnet a été maintenue à $60 \mathrm{~cm} \mathrm{H}_{2} \mathrm{O}$. La morbidité pharyngo-laryngienne postopératoire (mal de gorge, difficulté d'avaler, irritation de la bouche, douleur au cou/à la mâchoire, enrouement) a été évaluée à deux, 24 et 48 h par des expérimentateurs impartiaux.

Résultats : Le nombre d'essais nécessaires pour insérer le masque et la durée de l'anesthésie ont été similaires dans les deux groupes. Le mal de gorge a été plus fréquent avec le MLI à deux heures (44 vs 15 $\%, P=0,01$ ), à $24 h$ (59 vs $21 \%, P=0,008)$ et à 48 h (34 vs 3 $\%, P=0,005)$. L'irritation de la bouche a été plus fréquente aussi avec le $M L I$ à deux heures ( 16 vs $0 \%, P=0,02$ ) et à 24 h ( 12 vs 0 $\%, P=0,04)$, mais non à 48 h (6 vs $3 \%)$. La difficulté d'avaler se retrouve plus souvent avec le $\mathrm{MLI}$ à deux heures (25 vs $0 \%, P=$ 0,04 ), mais non à $24 \mathrm{~h}$ (3 I vs $3 \%$ ) ni à 48 h ( 12 vs $9 \%$ ). L'incidence de douleur au coulà la mâchoire n'a pas présenté de différence intergroupe ( $M L I$, 3-12 \%; $M L, 0-3 \%$ ), ni l'enrouement ( $M L I, ~ 12-31 \%$; ML, 16-18\%). II n'y a pas eu de corrélation entre la morbidité pharyngo-laryngienne postopératoire et la durée de l'anesthésie.

Conclusion : La morbidité pharyngo-laryngienne est plus élevée avec le MLI qu'avec le ML à la suite d'une anesthésie qui dure une ou deux heures.

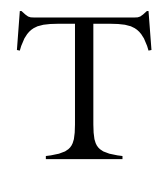

HE intubating laryngeal mask (ILM) is a new airway device designed to have better intubation characteristics than the classic laryngeal mask airway (LMA). ${ }^{1}$ The prima-

From the Department of Anaesthesia, Pain Clinic, and Clinical Toxicology, ${ }^{*}$ Mito Saiseikai General Hospital, Ibaraki, Japan; and the University of Queensland, Department of Anaesthesia and Intensive Care, $†$ Cairns Base Hospital, Cairns, Australia.

Address correspondence to: Prof. J. Brimacombe, University of Queensland, Department of Anaesthesia and Intensive Care, Cairns Base Hospital, The Esplanade, Cairns 4870, Australia. Phone: 61740 506960; Fax: 61740 311628; E-mail: jbrimacombe@austarnet.com.au Support was received solely from institutional and/or departmental resources.

Accepted for publication November 9, 2000.

Revision accepted March 11, 2001. 
ry role of the ILM is as an airway intubator, but it has a potential role as an alternative to the LMA in routine anesthesia practice since placement is conceptually easier and does not require insertion of the fingers in the patient's mouth. ${ }^{2}$ Unlike the LMA, which has a soft silicone tube, the ILM has a rigid silicone coated steel tube. In a recent study, Keller and Brimacombe ${ }^{3}$ found that the ILM exerted greater pressures against the pharyngeal mucosa than the LMA and suggested that the ILM was unsuitable for routine anesthesia practice. In the following randomised, double- blind study, we compare postoperative pharyngolaryngeal morbidity with the LMA and ILM.

\section{Methods}

Sixty-five female patients (ASA physical status class I or II, aged $18-80 \mathrm{yr}$ ) scheduled to undergo balanced regional anesthesia for gynecological laparotomy expected to last one to two hours were randomly assigned (by opening a sealed envelope) for airway management with either the ILM or LMA. Patients were excluded if they had oropharyngeal/cervical pathology, or had jaw, neck, mouth or upper respiratory tract symptoms in the previous ten days. Institutional Ethical Committee approval and written informed consent was obtained. Airway management was by anesthesiologists with experience of greater than 300 uses with each device. All ILM and LMAs used in the study were sterilised by steam autoclaving and had passed the pre-use check tests.

Premedication was with diazepam $5 \mathrm{mg}$ and roxatidine $\left(\mathrm{H}_{2}\right.$-blocker $) 75 \mathrm{mg}$ po $1.5 \mathrm{hr}$ preinduction. An epidural catheter was inserted at the L2/L3 interspace and $3 \mathrm{~mL}$ of $1.5 \%$ lidocaine with 1:200.000 epinephrine given as a test dose. Patients were placed in the supine position with the head-neck on a pillow $7 \mathrm{~cm}$ in height. A standard anesthesia protocol was followed and routine monitoring applied. Patients were induced with lidocaine $0.5 \mathrm{mg} \cdot \mathrm{kg}^{-1}$, fentanyl $2 \mu \mathrm{g} \cdot \mathrm{kg}^{-1}$ and propofol $2.5 \mathrm{mg} \cdot \mathrm{kg}^{-1}$. Maintenance was with oxygen $33 \%$ and sevoflurane $1-3 \%$ in nitrous oxide. Humidification was with a bacterial filter placed between the anesthesia breathing system and the airway device. Fresh gas flow was $3 \mathrm{~L} \cdot \mathrm{min}^{-1}$. The patient was face mask ventilated for one minute before ILM/LMA insertion. Face mask ventilation was graded as: easy (Guedel airway not required); moderate (Guedel airway required), difficult (Guedel airway plus jaw thrust required) and failed (failure to ventilate, alternative technique required). The ILM/LMA (size 4 only) was inserted and fixed using the manufacturer's recommended techniques. ${ }^{4,5} \mathrm{~A}$ water based jelly was used for lubrication. The number of insertion attempts were recorded (maximum three allowed). The ILM/LMA cuff was inflated with air to an intracuff pressure of 60 $\mathrm{cm} \mathrm{H}_{2} \mathrm{O}$ and the cuff volume noted. The intracuff pressure was maintained at approximately $60 \mathrm{~cm} \mathrm{H} \mathrm{H}_{2} \mathrm{O}$ throughout the surgery by intermittent withdrawal of air. Intracuff pressure was measured using an arterial pressure transducer attached to the pilot balloon. ${ }^{6}$ Oropharyngeal leak pressure and fiberoptic position were measured before the start of surgery. Oropharyngeal leak pressure was measured by closing the expiratory valve of the circle system at a fixed gas flow of $3 \mathrm{~L} \cdot \mathrm{min}^{-1}$ and noting the airway pressure at which the dial on a calibrated aneroid manometer reached equilibrium. ${ }^{7}$ The fibreoptic view was scored as follows: 4 (only vocal cords visible), 3 (vocal cords plus posterior epiglottis visible), 2 (vocal cords plus anterior epiglottis visible), and 1 (vocal cords not seen). ${ }^{8}$ Patients were allowed to spontaneously ventilate during surgery. Oropharyngeal suctioning was avoided. Thirty minutes before the end of the surgery, morphine 50 $\mu \mathrm{g} \cdot \mathrm{kg}^{-1}$ with $7 \mathrm{~mL}$ of $0.5 \%$ bupivacaine was given epidurally. The ILM/LMA were removed when the patient was able to open her mouth on command. Any blood detected on the ILM/LMA was noted. Postoperative analgesia was with buprenorphine $0.2 \mathrm{mg}$ with $7 \mathrm{~mL}$ of saline given epidurally as a top-up by investigators blinded to the type of device used. Oxygen was given via a Hudson-type face mask at $2-4 \mathrm{~L} \cdot \mathrm{min}^{-1}$ until patients were discharged to the ward. Intraoperative data was collected by unblinded observers. Patients were unaware of the device used.

Postoperative pharyngolaryngeal morbidity was assessed at two, 24 and $48 \mathrm{hr}$ by investigators blinded to the devices inserted. Sore throat, sore mouth, sore neck/jaw, difficulty swallowing and hoarseness were graded using a 4-point scale. Sore throat was graded as: $0=$ no sore throat (nil); $1=$ less severe than with a cold (mild); $2=$ similar to that noted with a cold (moderate); $3=$ more severe than with a cold (severe). Sore mouth and sore neck/jaw was graded as: $0=$ nil; $1=$ mild; $2=$ moderate; $3=$ severe. Swallowing difficulty was graded as: $0=$ no difficulty (nil); $1=$ discomfort at swallowing (mild); 2 =pain at swallowing (moderate), $3=$ severe pain at swallowing (severe). Hoarseness was graded as: $0=$ no hoarseness (nil); $1=$ noted by a patient (mild); $2=$ obvious to observer (moderate); $3=$ aphonia (severe).

Sample size was to detect a $20 \%$ difference in sore throat based on data from previous studies reporting a $15 \%$ incidence of sore throat with the $\mathrm{LMA}^{9}$ and a $50 \%$ incidence $^{10}$ with the ILM for a type I error of 0.05 and a power of 0.8. Descriptive data were tested using a two-tailed independent $t$ test. Categorical data were tested using a Chi-square test. The Mann- 
TABLE Incidence of postoperative pharyngolaryngeal morbidity for the intubating laryngeal mask airway (ILM) and the classic laryngeal mask airway (LMA). Data are numbers and percentage.

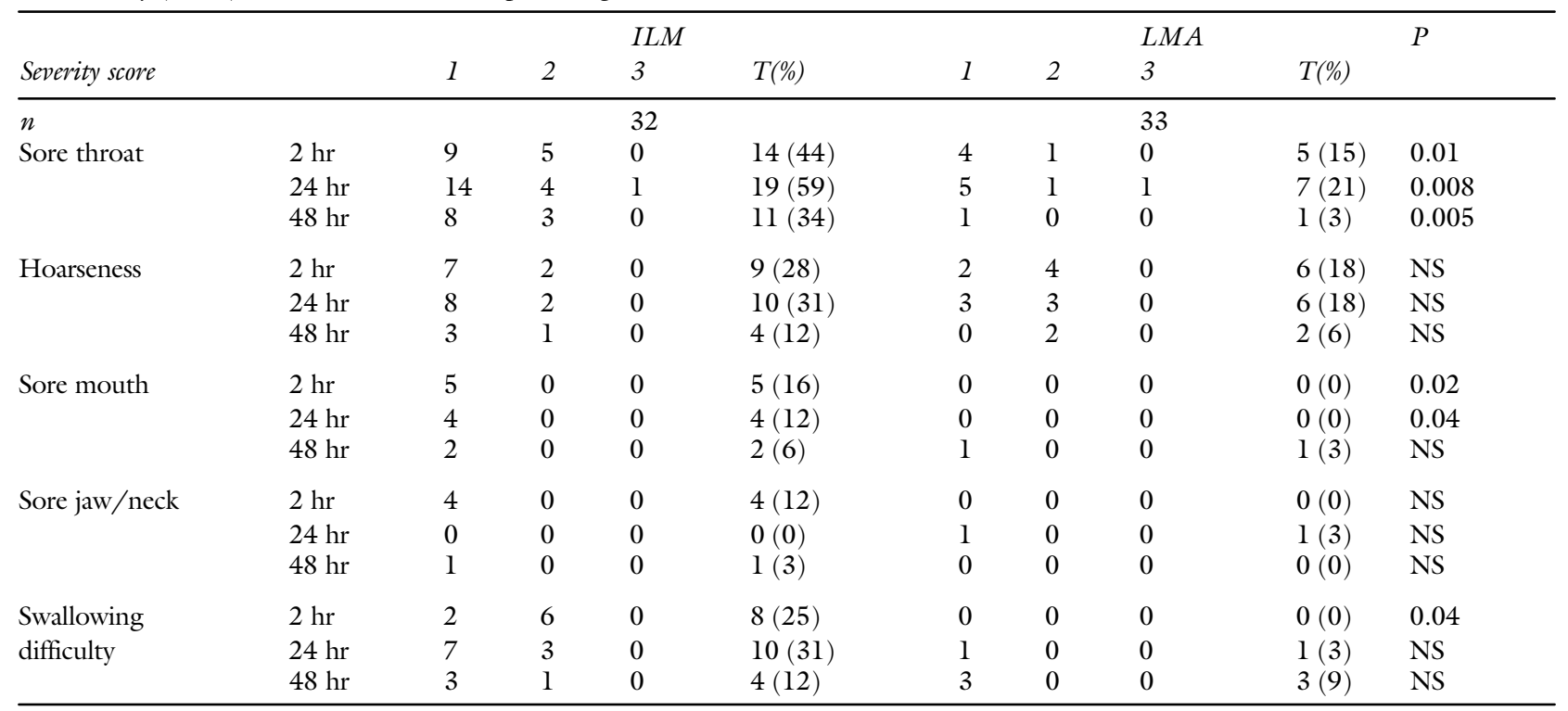

Severity score: $1=$ mild; $2=$ moderate; $3=$ severe; $\mathrm{T}(\%)=$ total (percentage) .

Whitney U-test was used for the ordinal data. The Spearman's rank correlation was used to test correlations between the duration of anesthesia and the severity of the upper airway complications. Unless otherwise noted, data is presented as mean \pm SD. Significance was taken as $P<0.05$.

\section{Results}

There were no demographic differences between groups. Five anesthesiologists participated in the study and each conducted 3-40 cases. The mean \pm SD for age, height and weight for the ILM/LMA group was $40 \pm 15 \mathrm{yr} ; 44 \pm 13 \mathrm{yr}, 158 \pm 7 \mathrm{~cm} ; 157 \pm 7 \mathrm{~cm}$ and $60 \pm 12 \mathrm{~kg} ; 57 \pm 11 \mathrm{~kg}$ respectively. There were equal number of smokers in each group (ILM, $n=23$; LMA, $n=26$ ). The duration of anesthesia (ILM, $105 \pm 35$ min vs LMA, $103 \pm 59 \mathrm{~min}$ ), mask ventilation score (4/3/2/1 n; ILM, 27/5/0/0 vs LMA, 29/3/1/0) the number of insertion attempts $(1 / 2 / 3 n$; ILM, 29/3/0 vs LMA, 32/1/0), cuff volume (ILM, $21 \pm$ $3 \mathrm{~mL}$ vs $20 \pm 3 \mathrm{~mL})$ and fibreoptic score $(4 / 3 / 2 / 1 \mathrm{n}$; ILM, 20/0/7/5 vs LMA, 14/6/12/1) were similar between groups. Oropharyngeal leak pressure was greater for the ILM $\left(24 \pm 5\right.$ vs $19 \pm 5 \mathrm{~cm} \mathrm{H}_{2} \mathrm{O}, P$ $<0.0001)$. Blood was detected upon removal in three patients in the ILM group and in two patients in the LMA group. Postoperative pharyngolaryngeal morbidity data is presented in the Table. Sore throat was more common for the ILM at two, 24 and $48 \mathrm{hr}$. Sore mouth was more common for the ILM at two and 24 $\mathrm{hr}$, but not at $48 \mathrm{hr}$. Difficulty swallowing was more common for the ILM at two hours, but not at 24 and $48 \mathrm{hr}$. There was no difference in the incidence of sore jaw/neck and hoarseness between groups. There was no correlation between postoperative pharyngolaryngeal morbidity and 1) duration of anesthesia; 2) mask ventilation score or 3 ) those patients who had two or more airway devices inserted - i.e., a Guedel airway plus the randomised device or more than one attempt with the randomized device. There were no significant differences in airway morbidity among anesthesiologists. Severe airway morbidity was only documented in one patient and this improved within $48 \mathrm{hr}$.

Discussion

Our data show that postoperative pharyngolaryngeal morbidity is more common with the ILM than the LMA. Although this supports the suggestion that the ILM is less suitable for routine anesthesia practice than the LMA, ${ }^{3}$ it should be noted that only one patient had severe airway morbidity and it is unlikely that mild or moderate morbidity would prevent discharge. There are no formal studies determining the incidence of postoperative pharyngolaryngeal morbidity with the ILM, but Nakazawa et al. ${ }^{1}$ found a high incidence of pharyngeal edema when the ILM was left in situ following its use as an airway intubator and Shung et al. ${ }^{10}$ found there was a high incidence of sore throat 
following its use for awake intubation. The incidence of pharyngolaryngeal morbidity for the LMA was similar to a previous study where the LMA cuff was inflated to half the maximum recommended cuff volume. ${ }^{12}$ Mucosal pressures are generally higher for the ILM compared with the LMA over the range of cuff volumes and are always greater than $157 \mathrm{~cm} \mathrm{H}_{2} \mathrm{O}$ where the curved metal tube pressed into the posterior oropharyngeal wall. ${ }^{3}$ This is much higher than the perfusion pressure of the posterior pharyngeal wall that is between 34 and $80 \mathrm{~cm} \mathrm{H}_{2} \mathrm{O} \cdot{ }^{13}$ It is likely that the increase in pharyngolaryngeal morbidity is related to pharyngeal ischemic damage given that insertion success rates and macroscopic airway trauma were similar for both devices. However, it is possible that the difference is related to microscopic airway trauma during insertion. Interestingly, we found that there was no relationship between duration of anesthesia and airway morbidity. Like the tracheal mucosa, ${ }^{14}$ the level of pressure and its duration of application probably determine the extent of pharyngeal mucosal injury. It may be that the range of anesthesia duration was too small to detect this effect and it is generally considered that pressure is thought to be more important in causing trauma than time. ${ }^{14}$

Our data show that the oropharyngeal leak pressure is greater for the ILM compared with the LMA. This confirms the findings of Keller and Brimacombe ${ }^{3}$ who suggested that this might be related to the increased mucosal pressure exerted by the ILM. Interestingly, we found that oropharyngeal leak pressure was greater even when the intracuff pressures are similar. Our data show that fibreoptic position is similar for the ILM and LMA. This contrasts with the findings of Keller and Brimacombe that showed that fiberoptic position was superior for the LMA. ${ }^{3}$ These interstudy differences may be related to different size selection strategies or different skill levels with the ILM.

Our study has a number of limitations. First, it was conducted on patients receiving postoperative epidural analgesia and it is possible that that incidence of pharyngolaryngeal morbidity would have been lower if patients had received systemic analgesia. Second, the duration of the procedure was approximately $1.5 \mathrm{hr}$ and our findings may not apply to patients having short procedures. Third, some researchers have detected differences in pharyngolaryngeal morbidity between males and females with the LMA ${ }^{15}$ and our data may not necessarily apply to males. Fourthly, oropharyngeal leak pressure was higher for the ILM and it is possible that morbidity would have been lower if intracuff pressure had been reduced to provide equal oropharyngeal leak pressure between devices. However, it has been shown that the area of highest mucosal pressure for the ILM (posterior oropharyngeal wall) does not vary with intracuff pressure/cuff volume. ${ }^{3}$ Finally, some clinicians might consider use of laryngeal mask devices inappropriate for gynecological laparotomy. However, the uneventful use of the LMA for gynecological laparotomy in 644 patients has been reported. ${ }^{16}$ Our patients were not considered to be at risk of aspiration.

We conclude that pharyngolaryngeal morbidity is more common with the ILM than the LMA following anesthesia lasting one to two hours.

\section{References}

I Brain AIJ, Verghese C, Addy EV, Kapila $A$ The intubating laryngeal mask. I: development of a new device for intubation of the trachea. Br J Anaesth 1997; 79: 699-703.

2 Brain AIJ, Verghese C, Addy EV, Kapila A, Brimacombe $J$. The intubating laryngeal mask. II: a preliminary clinical report of a new means of intubating the trachea. $\mathrm{Br}$ J Anaesth 1997; 79: 704-9.

3 Keller C, Brimacombe J. Pharyngeal mucosal pressures, airway sealing pressures, and fiberoptic position with the intubating versus the standard laryngeal mask airway. Anesthesiology 1999; 90: 1001-6.

4 Brain AIJ. LMA - Fastrach ${ }^{\mathrm{TM}}$ Instruction Manual. The Laryngeal Mask Company Ltd, Henley-on-Thames, Intavent Research Ltd, UK, 1997.

5 Brimacombe JR, Brain AIJ, Berry AM. The laryngeal mask instruction manual for anaesthesia. Henley-onThamas, Intavent Research Ltd, UK, 1999.

6 Brimacombe J, Keller C Laryngeal mask airway size selection in males and female: ease of insertion, oropharyngeal leak pressure, pharyngeal mucosal pressures and anatomical position. Br J Anaesth 1999; 82: 703-7.

7 Keller C, Brimacombe JR, Keller K, Morris R A comparison of four methods for assessing airway sealing pressure with the laryngeal mask airway in adult patients. Br J Anaesth 1999; 82: 286-7.

8 Brimacombe J, Berry A A proposed fiber-optic scoring system to standardize the assessment of laryngeal mask airway position (Letter). Anesth Analg 1993; 76: 457.

9 Brimacombe JR, Brimacombe JC, Berry AM, et al. A comparison of the laryngeal mask airway and cuffed oropharyngeal airway in anesthetized adult patients. Anesth Analg 1998; 87: 147-52.

10 Shung J, Avidan MS, Ing R, Klein DC, Pott L. Awake intubation of the difficult airway with the intubating laryngeal mask airway. Anaesthesia 1998; 53: 645-9.

11 Nakazawa K, Tanaka N, Ishikawa S, et al. Using the intubating laryngeal mask airway (LMA-Fastrach ${ }^{\mathrm{TM}}$ ) for blind endotracheal intubation in patients undergoing 
cervical spine operation. Anesth Analg 1999; 89:

1319-21.

12 Brimacombe J, Holyoake L, Keller C, et al. Emergence characteristics and postoperative laryngopharyngeal morbidity with the laryngeal mask airway: a comparison of high versus low initial cuff volume. Anaesthesia 1999; 55: 338-43.

13 Brimacombe J, Keller C, PÇ Pühringer F. Pharyngeal mucosal pressure and perfusion. A fiberoptic evaluation of the posterior pharynx in anesthetized adult patients with a modified cuffed oropharyngeal airway. Anesthesiology 1999; 91: 1661-5.

14 Nordin $U$. The trachea and cuff induced tracheal injury. An experimental study on causative factors and prevention. Acta Otolaryngol Suppl 1976; 345: 1-71.

15 Nott MR, Noble PD, Parmar M. Reducing the incidence of sore throat with the laryngeal mask airway. Eur J Anaesthesiol 1998; 15: 153-7.

16 Verghese C, Brimacombe JR. Survey of laryngeal mask airway usage in 11,910 patients: safety and efficacy for conventional and nonconventional usage. Anesth Analg 1996; 82: 129-33. 